\title{
Microstructure Evolution During Internal Reduction of Polycrystalline Nickel-doped Yttria-Stabilized Zirconia
}

\author{
Amy Morrissey ${ }^{\mathrm{a}}$, James R. O'Brien ${ }^{\mathrm{b}}$, Ivar E. Reimanis ${ }^{\mathrm{a}, *}$ \\ ${ }^{a}$ Colorado Center for Advanced Ceramics, Metallurgical and Materials Engineering \\ Department, Colorado School of Mines, Golden, CO 80401, USA \\ ${ }^{b}$ Off Grid Research, 6501 Goodwin Street, San Diego, CA 92111
}

\begin{abstract}
The nucleation and growth of metallic particles within metal-doped oxides in reducing conditions is relevant to the processing of materials for catalysis, fuel cells, and structural applications. Here, the precipitation of metallic nickel during the internal reduction of nickel-doped yttria stabilized zirconia is studied with electron microscopy and SQUID magnetometry. It is shown that the microstructure evolution proceeds in three distinct stages, each with its own kinetics description, dependent on the porosity and grain size. 0.5 molar percent $\mathrm{NiO}$ doped YSZ was synthesized, sintered, pressed into pellets, and then exposed to $1000^{\circ} \mathrm{C}$ in $2 \% \mathrm{H}_{2}$ for various times. Metallic $\mathrm{Ni}^{0}$ particles $(>100 \mathrm{~nm})$ are first formed in pores connected to grain boundaries; subsequently, metallic $\mathrm{Ni}^{0}$ particles $(20-50 \mathrm{~nm})$ precipitate at grain boundaries; and finally, superparamagnetic $\mathrm{Ni}^{0}$ particles $(<10 \mathrm{~nm})$ form within the bulk YSZ grains. The transitions between stages depend upon concentration gradients and electrostatic potentials that act upon the relevant transporting species, namely oxygen vacancies, electrons, nickel ions and zirconium vacancies.
\end{abstract}

Keywords: Reduction; Yttria-stabilized zirconia polycrystal; Nickel;

Nanoparticles; SQUID magnetometry

* Corresponding author
Email address: reimanis@mines.edu (Ivar E. Reimanis)

Preprint submitted to Journal of ${ }^{A} T_{E} X$ Templates

November 6, 2015

(C) 2015. This manuscript version is made available under the Elsevier user license http://www.elsevier.com/open-access/userlicense/1.0/ 


\section{Introduction}

The process of internal reduction, sometimes also referred to as partial reduction, is a convenient and potentially powerful way to make metal-ceramic composites for diverse applications [1 6]. In internal reduction, a mixed metal 5 oxide solid solution is exposed to a reducing environment at elevated temperature such that the most noble of the metal cations reduces its oxidation state, leading to the precipitation of a second phase within the less noble metal oxide. When the oxygen partial pressure is low enough to form a metal, but not so low as to reduce the parent oxide, the resulting microstructure leads to a metal particulate reinforced ceramic with a microstructure that may exhibit enhanced structural, catalytic or other functional properties [7-11]. The process is more complex than direct reduction whereby $\mathrm{NiO}$ particles in a YSZ matrix converts to Ni metal particles [12]. Accordingly, the mass transport and kinetics describing the process are distinctly different from those of direct reduction. [13, 14. Typically, it occurs by the growth of a reaction zone from the surface to the interior, described by parabolic kinetics, and rate-limited by the diffusion of cations, anions, or electronic charge carriers through the thickness of the reacted zone. The process has been well-described in homogeneous systems such as glass presence of microstructural features such as grain boundaries and porosity, as they introduce space charge layers and additional pathways for diffusion that may modify nucleation and growth conditions [21,22. In highly doped systems, like yttria-stabilized zirconia (YSZ), the intrinsic defect concentrations from the 25 dopant may be several orders of magnitude higher than the extrinsic defect concentrations that are introduced by the externally applied chemical potential gradient [23]. Particularly when high concentrations of intrinsic defects exist, the mass transport of charged species is dominated by an electrical potential 24. 
use in catalyst systems as well as their use as anodes in solid oxide fuel cells (SOFCs) 25 30]. For SOFCs, NiO is typically mixed with YSZ, co-fired in air to partial density, and then exposed to a reducing atmosphere to directly convert $\mathrm{NiO}$ to metallic $\mathrm{Ni}\left(\mathrm{Ni}^{0}\right)$. Invariably, some $\mathrm{NiO}$ dissolves in $\mathrm{YSZ}$ during

35 the air firing step. Subsequently, $\mathrm{Ni}^{0}$ exsolves during the reduction step via a process of internal reduction. In studies with compositions below or near the solubility limit of $\mathrm{NiO}$ in YSZ (about 2 molar percent [31, 32]) it is possible to produce nanometer size dispersions of $\mathrm{Ni}^{0}$ in YSZ [33, 34]. Depending on the starting YSZ microstructure and the specific reducing conditions, the possible 40 size and distribution of $\mathrm{Ni}^{0}$ particles one can engineer is potentially enormous. The present study examines internal reduction in a polycrystalline $\mathrm{NiO}$ dopedYSZ containing a small amount $(\sim 5 \%)$ of porosity. 10 YSZ (10 molar percent $\mathrm{Y}_{2} \mathrm{O}_{3}$ in $\mathrm{ZrO}_{2}$ ) was chosen over lower amounts of $\mathrm{Y}_{2} \mathrm{O}_{3}$ to ensure stability of the cubic phase 35. 0.5 molar percent $\mathrm{NiO}$ was chosen because it is well below

45 the solid solubility limit, yet high enough to facilitate detection by electron microscopy and magnetometry. It is shown that three distinct stages of internal reduction occur.

\section{Experimental Procedure}

Specimens in this study were prepared by sintering high purity powders that were synthesized by chemical methods described elsewhere [36]. All compositions were $0.5 \mathrm{~mol} \% \mathrm{NiO}$ in $10 \mathrm{~mol} \% \mathrm{Y}_{2} \mathrm{O}_{3}$ stabilized $\mathrm{ZrO}_{2}$ (10YSZ). Pellets $19 \mathrm{~mm}$ in diameter and $4 \mathrm{~mm}$ thick were formed in a stainless steel die with a uniaxial press (Carver, Inc., Wabash, IN, USA). The pellets were buried in 0.5 molar percent $\mathrm{NiO}$-doped 10YSZ powders in high purity $(99.8 \%$ ) alumina

${ }_{55}$ (CoorsTek, Golden, CO, USA) containers at $3^{\circ} \mathrm{C} \min ^{-1}$ to $1500^{\circ} \mathrm{C}$ for $4.5 \mathrm{~h}$ in air, conditions which result single phase YSZ with nickel completely in solid solution or as ions at internal interfaces, such as grain boundaries or pore surfaces. Magnetometry measurements reveal that no nickel exists as an ordered oxide; only disordered $\mathrm{Ni}^{2+}$ ions are present 32 . The density was measured to 
be $95.6 \%$ theoretical as measured by the Archimedes method. X-ray diffraction confirmed that the as-sintered material was single phase cubic zirconia [36]. The grain size was measured by the linear intercept method on SEM micrographs (Figure 1 to be $5.3 \pm 0.5 \mu \mathrm{m}$. The pore size and spacing was quantified with image analysis: the average pore radius is $167 \mathrm{~nm} \pm 81 \mathrm{~nm}$, and the average

${ }_{65}$ spacing between pores, based on the density and pore size, is $1.5 \mu \mathrm{m}$. Previous research suggests that the pore surfaces are sites for $\mathrm{Ni}^{2+}$ ions [37.

Laser pulse atom probe tomography (APT) to characterize the $\mathrm{Ni}^{2+}$ ion distribution in as-sintered samples was performed prior to reduction treatments using 40 pJ laser energy and $40 \mathrm{~K}$ specimen base temperature (Cameca, LEAP and boundaries were prepared using focused ion beam (FIB) milling (FEI Helios Nanolab 600i, Hillsboro, OR). Data analysis was performed using CAMECA IVAS v.3.2.6. software.

Internal reduction experiments were performed on sintered pellets in a high 75 purity (99.8\%) alumina reactor tube (CoorsTek, Golden, CO) and tube furnace (ATS, Butler, PA). Gas flow (99.998\% Ar or $2 \% \mathrm{H}_{2} / \mathrm{Ar}$ balance) was regulated with a solenoid valve and mass flow controller calibrated to the gas composition (MKS, Andover, MA). Conditions were chosen to produce a partial pressure of oxygen on the order of $10^{-19}$ atm, a value calculated to be sufficiently low to ${ }_{80}$ lead to internal reduction [38. The pellet was heated in $100 \mathrm{sccm}$ flowing $\mathrm{Ar}$ at $5^{\circ} \mathrm{C} \min ^{-1}$ to $1000^{\circ} \mathrm{C}$. At $1000^{\circ} \mathrm{C}$, the inlet gas was switched to $2 \% \mathrm{H}_{2}$. The inlet gas enters in the back of the reactor tube, flowing over the pellet specimen, and is then exhausted through the face plate. A thermocouple and oxygen sensor is positioned near the pellet inside the reactor tube. The pellets were soaked in $100 \mathrm{sccm}$ flowing $2 \% \mathrm{H}_{2}$ gas for various times $(0.5,5,10,25,50$, 66 , and $75 \mathrm{~h}$ ). The measured oxygen partial pressure inside the reactor tube was approximately $10^{-19}$ atm. Following the reduction hold time, the reactor tube was purged with $100 \mathrm{sccm}$ flowing Ar until a temperature of $50^{\circ} \mathrm{C}$ was achieved. 
a higher oxygen partial pressure and at lower temperatures. Table 1 summarizes the various conditions. While maintaining constant temperature of $1000^{\circ} \mathrm{C}$, the oxygen partial pressure was increased to approximately $10^{-15}$ atm by bleeding Ar gas into the reactor tube during the reduction treatment. Two additional 95 experiments were performed at $900^{\circ} \mathrm{C}$ and $800^{\circ} \mathrm{C}$ while maintaining constant oxygen partial pressure of approximately $10^{-19} \mathrm{~atm}$. Times were $0.5,5,10$, and $25 \mathrm{~h}$. The emphasis of these additional studies is to understand the effect of oxygen partial pressure and temperature on the reduction reaction.

Pellets were cross-sectioned with a diamond saw, mounted in cold-set epoxy, polished, and observed visually and with optical microscopy. The specimens underwent a change in color from tan to gray upon reduction. The change in color proceeded from the surface towards the center with increase in heat treatment time. The depth of this color change was measured directly on the cross sectioned specimen under a low power optical microscope. The mass of $\mathrm{Ni}^{0}$ formed in each of the reduced specimens was quantified with superconducting quantum interference device (SQUID) magnetometry (MPMS-7, Quantum Design Inc., San Diego, CA, USA). Direct current (DC) susceptibility moment versus field curves were collected on a 50 to $100 \mathrm{mg}$ pellect section at $100 \mathrm{~K}$ to quantify the saturation magnetization [38. The diamagnetic response of 10YSZ was subtracted from the overall curve measured at $100 \mathrm{~K}$ to extract the ferromagnetic response which arises entirely from $\mathrm{Ni}^{0}$ [32]. The magnetic moment of metallic $\mathrm{Ni}^{0}$ is $57.50 \mathrm{emu} \mathrm{g} \mathrm{g}^{-1} 39$.

The metallic $\mathrm{Ni}^{0}$ particle size was determined with alternating current (AC) SQUID magnetometry (MPMS-7, Quantum Design Inc., San Diego, CA, USA), 115 as described below and in more detail in the Results section. AC susceptibility curves were collected on a 50 to $200 \mathrm{mg}$ section of pellet using an AC drive of $7 \mathrm{~Hz}, 100 \mu \mathrm{T}$ AC drive amplitude, zero DC field, and scanning temperature from $1.8 \mathrm{~K}$ to $250 \mathrm{~K}\left[38\right.$. The shape and magnitude of the real, $\chi^{\prime}$, and imaginary, $\chi^{\prime \prime}$, components versus temperature curves represent a combination of contributions ${ }_{120}$ from unreduced $\mathrm{Ni}^{2+}$ ions (paramagnetic), reduced metallic $\mathrm{Ni}^{0}$ single-domain particles ( $\leq 10 \mathrm{~nm}$, superparamagnetic), and reduced metallic $\mathrm{Ni}^{0}$ multi-domain 
particles ( > $100 \mathrm{~nm}$, ferromagnetic). The characteristic magnetic behavior is well-understood [39]. Deconvolution and modeling of each response contributing to the measured data is detailed in the results section.

Transmission electron microscopy (TEM) images were collected with a $200 \mathrm{kV}$ accelerating voltage TEM (Phillips (FEI) CM200, Hillsboro, OR) on specimens prepared by FIB.

\section{Results}

Representative APT reconstructions of specimens taken from the grain interior is shown in Figure 2. The distribution of $\mathrm{Ni}^{2+}$ ions appears random in the grain interior after 1.3 million counts. Extensive APT characterization revealed a uniform distribution of $\mathrm{Ni}^{2+}$ ions in the grain interior and grain boundary regions. 38.

The progression of a reaction front is optically visible as shown in Figure 3 for 135 a pellet that was exposed to $10^{-19}$ atm at $900^{\circ} \mathrm{C}$ for various times. The thickness of the reacted zone, easily measured because of the difference in color between the as-sintered condition (tan) and the reacted zone (gray), is summarized for four of the specimens in Figure 4 Error bars represent one standard deviation calculated from 20 measurements of the reaction zone thickenss. The longest time for each of the four data sets in Figure 4 represents the time it took for the entire specimen to turn gray. It is clear that lower $P_{\mathrm{O}_{2}}$ and higher temperature led to a higher rate of reaction (higher slopes in Figure 44. The significance for the decrease of the reaction rate when the $P_{\mathrm{O}_{2}}$ is increased from $10^{-19}$ atm to $10^{-15}$ atm is to show that a well-controlled environment is needed to achieve 145 internal reduction. Experimental results for pellets exposed to $10^{-19} \mathrm{~atm}$ at $800^{\circ} \mathrm{C}$ are not shown because the reaction did not visually progress at this temperature.

TEM of specimens from the data sets shown in Figure 4 revealed that $\mathrm{Ni}^{0}$ particles approximately 100 - $200 \mathrm{~nm}$ formed within the pre-existing pores in the YSZ (Figure 5). Extensive TEM of these same specimens showed that in only 
a few cases, $<20 \mathrm{~nm} \mathrm{Ni}^{0}$ particles were formed at grain boundaries away from pores, the same as those observed for longer reduction times, presented below. It was therefore concluded that the gray color of the reaction zone described above is due to the formation $\mathrm{Ni}^{0}$ particles in pre-existing YSZ pores. Inspection of the data reveals that they generally are parabolic in time, up to a certain time. As described in more detail in the Discussion, the precipitation of $\mathrm{Ni}^{0}$ within YSZ grain boundary pores is the first of three stages of reduction. Based on the parabolic growth rate observed (Figure 4), the kinetics are assumed to be diffusion limited.

Magnetic moment versus field curves for the pellet reduced at $1000^{\circ} \mathrm{C} P_{\mathrm{O}_{2}} \sim$ $10^{-19}$ atm at various times (Figure 6) show that the saturation magnetization, $\mathrm{M}_{S}$, (the plateau of the curves) increases with increasing reduction time. The precision of the SQUID magnetometry measurement is represented by the size of the data points. Since $\mathrm{M}_{S}$ is directly related to the mass of metallic $\mathrm{Ni}^{0}$, and because the initial amount of $\mathrm{Ni}^{2+}$ present $(0.5 \mathrm{~mol} \%)$ is known, the percent of reduction, defined as the percent conversion of $\mathrm{Ni}^{2+}$ to metallic $\mathrm{Ni}^{0}$, may be determined. $\mathrm{M}_{S}$ was determined for all the pellets and used to calculate the percent of reduction which is observed to depend strongly on the temperature and environment (Figure 7). Generally, the percent of reduction is linear with time except for very long times.

TEM of specimens reduced at times up to $50 \mathrm{~h}$ in pellets reduced at $1000^{\circ} \mathrm{C}$ $P_{\mathrm{O}_{2}} \sim 10^{-19}$ atm revealed that 20 to $50 \mathrm{~nm} \mathrm{Ni}{ }^{0}$ particles formed at YSZ grain boundaries (Figure 8 (a)), a second stage of internal reduction, for times $\geq 10 \mathrm{~h}$. Strain contrast was associated with every particle observed. These grain boundary precipitates were abundant throughout the specimens and did not exhibit a superparamagnetic behavior when measured with AC susceptibility. Longer reduction times led to larger $\mathrm{Ni}^{0}$ particle sizes for particles situated at the grain boundaries. The $\mathrm{Ni}^{0}$ particles at the pre-existing pores did not coarsen with time. TEM within YSZ grains revealed the presence of fine $\mathrm{Ni}^{0}$ particles (Figure 8(b)), but only for longer reduction times compared with times required for grain boundary particles to form. The formation of $<10 \mathrm{~nm} \mathrm{Ni}{ }^{0}$ particles 
within the YSZ grains represents a third stage of internal reduction as described in the Discussion. No strain contours were observed with these $\mathrm{Ni}^{0}$ particles, and each one had associated with it a pore of about the same size as the particle. A precipitation-free zone extending about $200 \mathrm{~nm}$ from the grain boundary was observed adjacent to most grain boundaries.

The real and imaginary part of the AC susceptibility for pellets reduced at $1000^{\circ} \mathrm{C}, P_{\mathrm{O}_{2}} \sim 10^{-19}$ atm for various times reveals information about the distribution of nickel (Figure 9). The precision of the SQUID magnetometry measurement is represented by the size of the data points. For the $5 \mathrm{~h}$ reduction time, the data follow a Curie-Weiss law, indicating the presence of a large number of disordered $\mathrm{Ni}^{2+}$ ions. Furthermore, these data show a gradual increase in $\mathrm{AC}$ susceptibility with temperature beyond about $100 \mathrm{~K}$, consistent with the presence of ferromagnetic $\mathrm{Ni}^{0}$ in the pre-existing pores (compare to Figure 5). In contrast, the $10 \mathrm{~h}$ reduced pellet shows the onset of a peak around $11 \mathrm{~K}$, a classic signature of superparamagnetic metallic $\mathrm{Ni}^{0} . \mathrm{Ni}^{0}$ particles may exhibit superparamagnetic behavior when the particle size is below about $20 \mathrm{~nm}$ [40]. These AC susceptibility results are consistent with the observation of very fine $\mathrm{Ni}^{0}$ particles in the grain interiors in TEM (Figure $8(\mathrm{a})$ ). The longer reduction times in Figure 9 show an increase in AC susceptibility and a shift of the peak to higher temperatures, revealing that the superparamagnetic particles coarsen with increased reduction time. The radius of metallic $\mathrm{Ni}^{0}$ particles can be calculated from the blocking temperature, $T_{B}$, which is the temperature at which the peak in AC susceptibility occurs in Figure 9 [39]:

$$
\mathrm{T}_{\mathrm{B}}=\frac{\mathrm{KV}}{25 k_{\mathrm{B}}}
$$

where $\mathrm{V}$ is the volume of a spherical particle, related directly to the particle radius, $k_{\mathrm{B}}$ is Boltzmann constant and $\mathrm{K}$ is the anisotropy constant for nickel [41]. A summary of the measured diameters of metallic $\mathrm{Ni}^{0}$ particles for reduction times up to $50 \mathrm{~h}$ is tabulated in Table 2. Superparamagnetic particles were only observed in specimens reduced at $1000^{\circ} \mathrm{C}, P_{\mathrm{O}_{2}} \sim 10^{-19}$ atm for $>10 \mathrm{~h}$ but $<$ $75 \mathrm{~h}$ (due to coarsening). At higher oxygen partial pressure $\left(P_{\mathrm{O}_{2}} \sim 10^{-15} \mathrm{~atm}\right)$ 
$\mathrm{Ni}^{0}$ precipitation within bulk YSZ was not observed, even up to $50 \mathrm{~h}$.

\section{Discussion}

195

200 ity significantly influence the progression of internal reduction, and dictate the resultant metal-ceramic composite microstructure. A careful inspection of the data reveals that internal reduction in polycrystalline NiO-doped YSZ occurs in three distinct stages, depicted in Figure 10 . In the first, metallic nickel $\left(\mathrm{Ni}^{0}\right)$ so aries). In this stage, the color of the specimen changes from tan to gray. Though a visible reaction front proceeds through the entirety of the pellet thickness, only approximately $15 \%$ of the total $\mathrm{Ni}^{2+}$ ions are exsolved in this stage. In the second stage, $\mathrm{Ni}^{0}$ forms at $\mathrm{YSZ}$ grain boundaries. In the last stage, $\mathrm{Ni}^{0}$ forms within the YSZ grains. The stages exhibit distinctly different kinetics, with different thermodynamic driving forces, and are thus discussed separately.

\section{Stage 1}

It has been previously established that diffusing species for internal reduction in YSZ are oxygen vacancies, electrons, and $\mathrm{Ni}^{2+}$ ions [12]. While the transference number of oxygen vacancies in bulk YSZ is much greater than that of electrons [42, the opposite is true at the grain boundaries where space charge effects dominate 43 48. In particular, the rate-limiting species along grain boundaries are expected to be oxygen vacancies. During stage 1 (Figure $9 \mathrm{a})$, it is proposed that oxygen vacancies and electrons diffuse along grain boundaries to pre-existing pores where they react with $\mathrm{Ni}^{2+}$ ions which have segregated at the pore surfaces in the as-processed material [37. $\mathrm{Ni}^{2+}$ ions at the pore surfaces are transported by surface diffusion to the intersection of the grain boundary and the pore where reduction occurs. Because surface diffusion is expected to be relatively high compared to grain boundary or bulk diffusion, 220 and the distances $\mathrm{Ni}^{2+}$ diffuses are small (on the order of the pore size), it must 
be that the overall reaction rate is limited by the diffusion of oxygen vacancies along the grain boundaries, consistent with previous results reported for NiYSZ [12]. It is noted that the size of the $\mathrm{Ni}^{0}$ particles formed $(100-200 \mathrm{~nm})$ is consistent with monolayer coverage of the pre-existing pore by $\mathrm{Ni}^{2+}$ ions prior to the reduction exposure 1

The observation that $\mathrm{Ni}^{0}$ particles form in pre-existing pores (Figure 5 prior to the formation of $\mathrm{Ni}^{0}$ at grain boundaries implies either that the grain boundaries in the as-sintered material do not contain $\mathrm{Ni}^{2+}$ ions prior to reduction, or that nucleation and growth of $\mathrm{Ni}^{0}$ at the grain boundary has a significant activation barrier, or both. The presence of strain contours around grain boundary saturated $\mathrm{Ni}^{0}$ particles indicates that there is likely an elastic strain energy component to the activiation energy for nucleation. Furthermore, atom probe tomography results show that $\mathrm{Ni}^{2+}$ ions are indeed not segregated at the grain boundaries compared with the bulk (Figure 2), meaning that $\mathrm{Ni}^{2+}$ ions must diffuse to the boundaries to form $\mathrm{Ni}^{0}$ particles. Therefore, the diffusion of $\mathrm{Ni}^{2+}$ ions to the grain boundaries (part of stage 2 described next) must be slower than the diffusion of oxygen vacancies and electrons to the pre-existing pores that contain abundant $\mathrm{Ni}^{2+}$ ions.

Data in Figure 4 allow a determination of the kinetics of the rate limiting 240 species, oxygen vacancy diffusion, along YSZ grain boundaries. It should be noted that if the specimen did not contain pre-existing pores, the slopes of the curves Figure 4 would represent precisely the reaction rate constants for oxygen vacancy diffusion. For parabolic kinetics, the reaction rate constant, $\mathrm{k}$, may be described by $\Delta \xi=\mathrm{kt}^{1 / 2}$, where $\Delta \xi$ is the (measured) reaction front thickness and $\mathrm{t}$ is time [2, 14. However, the pre-existing pores serve as a sink and one must account for the extra time needed to fill this sink. During this extra time, oxygen vacancies continue to diffuse along the grain boundary to the

\footnotetext{
${ }^{1}$ The $\mathrm{Ni}^{2+}$ monolayer coverage of a pore with diameter equal to $334 \mathrm{~nm}$ means that there will be $107 \mathrm{Ni}^{2+}$ ions available to react to form $\mathrm{Ni}^{0}$. Considering the density of $\mathrm{Ni}$ is $8.93 \mathrm{~g} / \mathrm{cm}^{3}$, the $\mathrm{Ni}^{0}$ particle size would be $63 \mathrm{~nm}$, consistent with the observed size.
} 
growing $\mathrm{Ni}^{0}$ particle at the pre-existing pores. The extra time is equal to the time it takes for an oxygen vacancy-electron pair to diffuse to the pore times the number of nickel atoms present. The latter is determined by the size of the particle $(100-200 \mathrm{~nm})$, the density of nickel $\left(8.93 \mathrm{~g} / \mathrm{cm}^{3}\right)$ and the atomic mass of nickel. Table 3 shows the reaction rate constant predicted with and without this consideration (uncorrected and corrected). It is clear that a model which does not account for the extra $\mathrm{Ni}^{2+}$ in the pores would underestimate the grain boundary diffusion of reactant species and overestimate the distance the reactant species travel. The corrected rate constant is on the order of magnitude of the reported diffusivity values of oxygen vacancies in YSZ [49]52].

The initiation of stage 1 reduction occurs almost instantaneously because the $\mathrm{Ni}^{2+}$ ions are already present at the surface and there is virtually no energy barrier for nucleation on the free surface of the pore. The completion of stage 1 may be determined by calculating the total mass of $\mathrm{Ni}^{0}$ particles in the pre-existing pores. The size and number of pores dictate the time. In the present specimens, monolayer $\mathrm{Ni}^{2+}$ coverage of the porosity means that stage 1 is complete once about $13 \%$ of the $\mathrm{Ni}^{2+}$ ions are reduced. This number is consistent with SQUID magnetometry (Figure 7) where it is observed that for the specimen with the fastest kinetics $\left(1000^{\circ} \mathrm{C}, P_{\mathrm{O}_{2}} \sim 10^{-19}\right.$ atm; open circles), about $15 \%$ of the $\mathrm{Ni}^{2+}$ is reduced to ferromagnetic $\mathrm{Ni}^{0}$ after $10 \mathrm{~h}$.

\section{Stage 2}

The onset of stage 2 reduction begins when $\mathrm{Ni}^{2+}$ ions diffuse to the grain 270 boundaries, and once any nucleation barrier is overcome. An estimate of the barrier for nucleation at the grain boundary compared with that in the bulk may be determined by calculating the ratio of the free energy of formation at the grain boundary to homogeneous free energy of formation. This ratio may be represented by the dihedral angle of the particle at the boundary [53]. An average dihedral angle of $120^{\circ}$ was measured from high-resolution STEM micrographs of three $\mathrm{Ni}^{0}$ particles, implying that the free energy of grain boundary 
nucleation requires one-third less energy than homogeneous nucleation, consistent with the observation that stage 2 occurs prior to stage 3 .

Unlike stage 1 , the formation of $\mathrm{Ni}^{0}$ particles at the boundary in stage 2 requires diffusion of the $\mathrm{Ni}^{2+}$ ions through the YSZ lattice to the boundary since the $\mathrm{Ni}^{2+}$ ions are shown to be evenly distributed throughout the microstructure (Figure 22). Due to the negative space charge potential in YSZ [21], the grain boundaries are presumably saturated with electrons that are available to react with $\mathrm{Ni}^{2+}$ ions that diffuse through the bulk YSZ. The $\mathrm{Ni}^{0}$ grain boundary precipitates coarsen with time to form single domain $\mathrm{Ni}^{0}$ particles, ultimately achieving sizes between 20 and $50 \mathrm{~nm}$. Presumably, the $\mathrm{Ni}^{0}$ particles are small enough during the initial formation to exhibit superparamagnetic behavior but this is not observed. The strain contours are indicative of an applied stress on the particles which can alter the doman structure and create magnetic anistropy [39. An increase in magnetic anistropy causes the peak in $\chi^{\prime}$ to shift to a higher blocking temperature value (Equation 1).

In the context of confirming that $\mathrm{Ni}^{2+}$ is the rate-limiting species in stage 2 , it is worthwhile considering the possible transport mechanism. It is generally agreed that $\mathrm{Ni}^{2+}$ ions in solid solution substitute for $\mathrm{Zr}^{4+}$ ions on the YSZ lattice [54, 55]. The following equation describes this defect reaction (KrogerVink notation).

$$
\mathrm{NiO} \stackrel{\mathrm{YSZ}}{\longrightarrow} \mathrm{Ni}_{\mathrm{Zr}}^{\prime \prime}+\mathrm{V}_{\mathrm{O}}^{\bullet \bullet}+\mathrm{O}_{\mathrm{O}}^{\times}
$$

Under reducing conditions, the formation of $\mathrm{Ni}^{0}$ must lead to the creation of vacant $\mathrm{Zr}^{4+}$ sites. Previous studies have shown that vacant $\mathrm{Zr}^{4+}$ sites form defect clusters with oxygen vacancies and that cation diffusion in YSZ occurs by the migration of these defect clusters [56 59]. The formation of such defect clusters during the formation of $\mathrm{Ni}^{0}$ particles at the grain boundary during reduction may be described by:

$$
\mathrm{Ni}_{\mathrm{Zr}}^{\prime \prime}+\mathrm{O}_{\mathrm{O}}^{\times}+2 \mathrm{e}_{\mathrm{gb}}^{\prime}+\mathrm{V}_{\mathrm{O}}^{\bullet \bullet} \longleftrightarrow \mathrm{Ni}_{\mathrm{gb}}^{0}+\left(\mathrm{V}_{\mathrm{Zr}}^{\prime \prime \prime \prime}+\mathrm{V}_{\mathrm{O}}^{\bullet \bullet}\right)^{\prime \prime}
$$

where $\left(\mathrm{V}_{\mathrm{Zr}}^{\prime \prime \prime \prime}+\mathrm{V}_{\mathrm{O}}^{\bullet \bullet}\right)^{\prime \prime}$ denotes the defect cluster and the subscript gb indicates the presence of the species at the grain boundary. Thus, every $\mathrm{Ni}^{2+}$ ion that is 
reduced to form $\mathrm{Ni}^{0}$ leads to a defect cluster whose presence contributes to the further diffusion of $\mathrm{Ni}^{2+}$ ions to the grain boundary. The linear trend between $\%$ reduced (which equates with volume) and time (Figure 7) implies zero-order rate kinetics which commonly result with heterogeneous reactions where very few species are in proximity to participate in the reaction but a source exists to supply more reactant species. 60] In this case, the grain boundaries are the source for oxygen vacancies and the grain interiors are the sink for the oxygen vacancy defect clusters.

\section{Stage 3}

In stage $3, \mathrm{Ni}^{2+}$ in the grain interior reacts to form superparamagnetic $\mathrm{Ni}^{0}$ particles (Figure 8 like those previously reported in NiO-YSZ [34. Kondo, et al 34 discussed possible reasons that a void was produced with each $\mathrm{Ni}^{0}$ particle. It is proposed here that the voids associated with the formation of superparamagnetic $\mathrm{Ni}^{0}$ particles must be the result of the following reaction describing stage 3 reduction:

$$
\left(\mathrm{V}_{\mathrm{Zr}}^{\prime \prime \prime \prime}+\mathrm{V}_{\mathrm{O}}^{\bullet \bullet}\right)^{\prime \prime}+\mathrm{Ni}_{\mathrm{Zr}}^{\prime \prime}+2 \mathrm{e}^{\prime}+\mathrm{V}_{\mathrm{O}}^{\bullet \bullet} \longleftrightarrow \mathrm{Ni}^{0}+\mathrm{V}_{\mathrm{Zr}}^{\prime \prime \prime \prime}+\left(\mathrm{V}_{\mathrm{Zr}}^{\prime \prime \prime \prime}+2 \mathrm{~V}_{\mathrm{O}}^{\bullet \bullet}\right)^{\times}
$$

The creation of vacant $\mathrm{Zr}^{4+}$ sites enhances the substitutional diffusion of $\mathrm{Ni}^{2+}$ to the $\mathrm{Ni}^{0}$ particle. The loss of a compound unit of $\mathrm{ZrO}_{2}$ explains the void formation upon formation of metallic nickel particles.

Even though stages 2 and 3 are both rate-limited by the diffusion of $\mathrm{Ni}^{2+}$ ions through the YSZ lattice, the detailed mechanisms are different (Figure 10). Stage 3 is effectively activated only when there exists a critical concentration of vacancy clusters that serve as nucleation sites for $\mathrm{Ni}^{0}$. A clue describing the stage 3 reaction mechanism is a precipitate free zone (PFZ) that is observed adjacent to the grain boundaries. It was first hypothesized that the PFZ observed is correlated to a depletion of $\mathrm{Ni}^{2+}$. However, the thickness of the PFZ exceeds the calculated diffusion distance for $\mathrm{Ni}^{2+}$ predicted by Fick's laws by an order of magnitude. An alternative hypothesis is that the PFZ is correlated 
to the absence of oxygen vacancies needed for nucleation sites. To explain this, one can calculate the electrostatic effect superimposed on the mass transport of $\mathrm{V}_{\mathrm{O}}^{\bullet \bullet}$ due to the space charge layer, $\lambda^{*}$, from [61]:

$$
\lambda^{*}=\lambda \sqrt{\frac{4 \mathrm{e}}{k_{\mathrm{B}} \mathrm{T}} \Delta \varphi}
$$

where the Debye length is $\lambda(40 \mathrm{~nm})$ and the electrochemical potential induced by the chemical potential gradient in oxygen activity is $\Delta \varphi(340 \mathrm{mV})$. Details of this calculation are presented elsewhere [38. The calculated $\lambda^{*}$ is around $140 \mathrm{~nm}$, approximately equal to the thickness of the PFZ. It is therefore likely

310 duction of polycrystalline nickel doped YSZ. How the reactant species diffuse through the polycrystal and the preferential nucleation sites for metallic $\mathrm{Ni}^{0}$ particles strongly depends upon microstructural features, such as pre-existing porosity and grain boundaries. Both surfaces and grain boundaries lower the mass transport due to space charge effects.

The reduction reaction occurs in three distinct stages and the result is a distribution of metallic $\mathrm{Ni}^{0}$ particles sizes in the reduced microstructure. $\mathrm{Ni}^{2+}$ ions exists as a monolayer in pre-existing porosity, and therefore the size of metallic 
$330 \mathrm{Ni}^{0}$ depends upon the size of the pore. The exsolution of $\mathrm{Ni}^{2+}$ requires time for diffusion of the ions to nucleation sites, first forming along grain boundaries. Once a critical vacancy concentration has been reached in the grain interior due to the reduction reaction, voids form due to the formation of vacancy defect clusters. These defect clusters create voids that provide nucleation sites

335 for very fine metallic $\mathrm{Ni}^{0}$ particles. The sensitivity of the reduction reaction to microstructural features provides a foundation for microstructural design by controlling porosity and grain size.

The influence of the electrical potential on mass transport is quantified to explain the precipitation free zone that is observed in the internal reduction microstructure. The reactant species are introduced by the gradient in oxygen partial pressure, and mass transport along the grain boundaries is preferred due to the space charge effect. The calculated space charge layer thickness is in good agreement with the experimental results of the PFZ thickness. In the PFZ there is an absence of defect clusters. Without defect clusters the nucleation energy 345 for metallic $\mathrm{Ni}^{0}$ is too high.

\section{Acknowledgements}

This research is funded by the National Science Foundation, Division of Materials Research, Ceramics Program, under Grant Number 1003030. Special thanks are extended to the Magnetics Group at NIST Boulder, CO, USA, for access to a SQUID magnetometer. A. Morrissey thanks Prof. Brian Gorman and Dr. Dave Diercks for atom probe tomography training; and Dr. Michael Sanders and Prof. Ryan O'Hayre for insightful discussions.

\section{References}

[1] A. E. Hughes, S. C. Jain, Metal colloids in ionic crystals, Adv. Phys. 28 (6) (1979) 717-828. doi:10.1080/00018737900101445 
[2] K. Ostyn, C. Carter, M. Koehne, H. Falke, H. Schmalzried, Internal Reactions in Oxide Solid Solutions, J. Am. Ceram. Soc. 67 (10) (1984) 679-685. doi:10.1111/j.1151-2916.1984.tb19682.x

[3] H. Schmalzried, M. Backhaus-Ricoult, Internal solid state reactions, Prog. Solid State Chem. 22 (1) (1993) 1-57. doi:10.1016/0079-6786(93) 90007-E

[4] E. Üstündağ, R. Subramanian, R. Vaia, R. Dieckmann, S. L. Sass, In situ formation of metal-ceramic microstructures, including metal-ceramic composites, using reduction reactions, Acta Metall. Mater. 41 (7) (1993) 21532161. doi:10.1016/0956-7151(93)90385-6

[5] R. Subramanian, E. Üständağ, S. L. Sass, R. Dieckmann, In-situ formation of metal-ceramic microstructures by partial reduction reactions, Solid State Ion. 75 (1995) 241-255. doi:10.1016/0167-2738(94)00148-L.

[6] C. A. Handwerker, J. S. Wallace, T. J. Foecke, U. R. Kattner, J. E. Blendell, In situ formation of composite microstructures, J. Microsc. 179 (3) (1995) 286-296. doi:10.1111/j.1365-2818.1995.tb03644.x.

[7] P. Hing, G. W. Groves, The strength and fracture toughness of polycrystalline magnesium oxide containing metallic particles and fibres, J. Mater. Sci. 7 (4) (1972) 427-434. doi:10.1007/BF02403406.

[8] J. Narayan, Y. Chen, Physical properties of oxides containing metal precipitates, Philos. Mag. A 49 (4) (1984) 475-492. doi:10.1080/ 01418618408236550

[9] R. A. Huggins, Materials science principles related to alloys of potential use in rechargeable lithium cells, J. Power Sources 26 (1-2) (1989) 109120. doi:10.1016/0378-7753(89)80020-5.

[10] W. H. Tuan, R. J. Brook, The toughening of alumina with nickel inclusions, J. Eur. Ceram. Soc. 6 (1) (1990) 31-37. doi:10.1016/0955-2219(90) 90032-B. 
[11] J. A. Smith, P. Limthongkul, L. Hartsuyker, S. Y. Kim, S. L. Sass,

[13] H. Schmalzried, W. Laqua, Multicomponent oxides in oxygen potential gradients, Oxid. Met. 15 (3-4) (1981) 339-353. doi:10.1007/BF01058834

[14] H. Schmalzried, Oxide Solid Solutions and its Internal Reduction Reactions, duction of (Ni,Mg)O and (Co,Mg)O solid solutions, J. Appl. Phys. 83 (5) (1998) 2719-2726. doi:10.1063/1.367036

[12] J. T. White, I. E. Reimanis, J. Tong, J. R. O'Brien, A. Morrissey, Internal Reduction of $\mathrm{Ni}^{2+}$ in $\mathrm{ZrO}_{2}$ Stabilized with $10 \mathrm{~mol} \% \mathrm{Y}_{2} \mathrm{O}_{3}$ Examined with VSM and SQUID Magnetometry, J. Am. Ceram. Soc. 95 (12) (2012) 40084014. doi:10.1111/j.1551-2916.2012.05441.x.

Ber. Bunsenges. phys. Chem. 88 (12) (1984) 1186-1191. doi:10.1002/ bbpc.198400046.

[15] J. Narayan, Y. Chen, R. Moon, Nickel Colloids in Reduced Nickel-Doped

口 Magnesium Oxide, Phys. Rev. Lett. 46 (22) (1981) 1491-1494. doi:10. 1103/PhysRevLett.46.1491

400 [16] M. Backhaus-Ricoult, S. Hagège, Internal reduction of $(\mathrm{Mg}, \mathrm{Cu}) \mathrm{O}$, Philos. Mag. A 67 (6) (1993) 1471-1493. doi:10.1080/01418619308225368.

[17] M. Backhaus-Ricoult, S. Hagèe, A. Peyrot, P. Moreau, Internal Reduction of Chromium-Doped $\alpha$-Alumina, J. Am. Ceram. Soc. 77 (2) (1994) 423430. doi:10.1111/j.1151-2916.1994.tb07010.x.

[18] M. Backhaus-Ricoult, Growth and equilibrium morphology of metal precipitates formed inside an oxide matrix, Interface Sci. 4 (3) (1997) 285-302. doi:10.1007/BF00240248.

[19] C. A. Handwerker, T. J. Foecke, J. S. Wallace, U. R. Kattner, R. D. Jiggets, Formation of alumina-chromia-chromium composites by a partial reduction reaction, Mater. Sci. Eng. A 195 (1995) 89-100. doi: 10.1016/0921-5093(94)06508-X. 
[20] R. L. A. Everman, R. F. Cooper, Internal Reduction of an Iron-Doped Magnesium Aluminosilicate Melt, J. Am. Ceram. Soc. 86 (3) (2003) 487494. doi:10.1111/j.1151-2916.2003.tb03326.x.

[21] X. Guo, Physical origin of the intrinsic grain-boundary resistivity of stabilized-zirconia: Role of the space-charge layers, Solid State Ion. 81 (3-4) (1995) 235-242. doi:10.1016/0167-2738(95)00180-E.

[22] J. Maier, Ionic conduction in space charge regions, Prog. Solid State Chem. 23 (3) (1995) 171-263. doi:10.1016/0079-6786(95)00004-E.

[23] K. Sasaki, J. Maier, Low-temperature defect chemistry of oxides. I. General aspects and numerical calculations, J. Appl. Phys. 86 (10) (1999) 54225433. doi:10.1063/1.371541.

[24] R. P. O'Hayre, S.-W. Cha, W. G. Colella, F. B. Prinz, Fuel Cell Fundamentals, 2nd Edition, John Wiley \& Sons, 2009, pp. 153-154.

[25] A. Kuzjukevics, S. Linderoth, Interaction of $\mathrm{NiO}$ with yttria-stabilized 口 zirconia, Solid State Ion. 93 (3-4) (1997) 255-261. doi:10.1016/ S0167-2738(96)00529-2.

[26] S. Aruna, M. Muthuraman, K. Patil, Synthesis and properties of Ni-YSZ cermet: anode material for solid oxide fuel cells, Solid State Ion. 111 (1-2) (1998) 45-51. doi:10.1016/S0167-2738(98)00187-8.

[27] T. Klemensø, M. Mogensen, Ni-YSZ Solid Oxide Fuel Cell Anode Behavior Upon Redox Cycling Based on Electrical Characterization, J. Am. Ceram.

口 Soc. 90 (11) (2007) 3582-3588. doi:10.1111/j.1551-2916.2007.01909. $\mathrm{X}$ 
[29] Q. Jeangros, A. Faes, J. B. Wagner, T. W. Hansen, U. Aschauer,

[30] Z. Jiao, N. Shikazono, N. Kasagi, Quantitative Characterization of SOFC

[35] W. G. Coors, J. R. O'Brien, J. T. White, Conductivity degradation of NiOcontaining 8YSZ and 10YSZ electrolyte during reduction, Solid State Ion. J. Van herle, A. Hessler-Wyser, R. E. Dunin-Borkowski, In situ redox cycle of a nickel-YSZ fuel cell anode in an environmental transmission electron microscope, Acta Mater. 58 (14) (2010) 4578-4589. doi:10.1016/j. actamat.2010.04.019. Nickel-YSZ Anode Microstructure Degradation Based on Focused-IonBeam 3d-Reconstruction Technique, J. Electrochem. Soc. 159 (3) (2012) B285-B291. doi:10.1149/2.045203jes

[31] S. Linderoth, N. Bonanos, Effects of Dissolution and Exsolution of Ni in YSZ, in: Arumugamnthiram, P. N. Kumta, S. K. Sundaram, G. Ceder (Eds.), Mater. Electrochem. Energy Convers. Storage, The American Ceramic Society, 2006, pp. 147-156. doi:10.1002/9781118370858.ch16.

[32] White, Nickel oxide in zirconia and yttria-stabilized zirconia studied with magnetometry, Ph.D. thesis, Colorado School of Mines (2011).

[33] S. Linderoth, N. Bonanos, K. V. Jensen, J. B. Bilde-Sørensen, Effect of NiOto-Ni Transformation on Conductivity and Structure of Yttria-Stabilized $\mathrm{ZrO}_{2}$, J. Am. Ceram. Soc. 84 (11) (2001) 2652-2656. doi:10.1111/j. 1151-2916.2001.tb01067.x.

[34] H. Kondo, T. Sekino, N. Tanaka, T. Nakayama, T. Kusunose, K. Niihara, Mechanical and Magnetic Properties of Novel Yttria-Stabilized Tetragonal Zirconia/Ni Nanocomposite Prepared by the Modified Internal Reduction Method, J. Am. Ceram. Soc. 88 (6) (2005) 1468-1473. doi:10.1111/j. 1551-2916.2005.00243.x. 
[36] A. Morrissey, Preparation of high purity doped oxides for fundamental studies, Master's thesis, Colorado School of Mines (2013).

[37] A. Morrissey, J. Tong, B. P. Gorman, I. E. Reimanis, Characterization of Nickel Ions in Nickel-Doped Yttria-Stabilized Zirconia, J. Am. Ceram. Soc. 97 (4) (2014) 1041-1047. doi:10.1111/jace.12839.

[38] A. Morrissey, The reduction of nickel doped fluorite and perovskite structured oxides, Ph.D. thesis, Colorado School of Mines (In preparation.).

[39] B. D. Cullity, C. D. Graham, Introduction to Magnetic Materials, 2nd Edition, Wiley-IEEE Press, Hoboken, N.J, 2008.

475 [40] C. P. Bean, J. D. Livingston, Superparamagnetism, J. Appl. Phys. 30 (4) (1959) S120-S129. doi:10.1063/1.2185850.

[41] F. C. Fonseca, G. F. Goya, R. F. Jardim, R. Muccillo, N. L. Carreo, E. Longo, E. R. Leite, Superparamagnetism and magnetic properties of Ni nanoparticles embedded in $\mathrm{SiO}_{2}$, Phys. Rev. B 66 (10) (2002) 1044061.

[42] M. J. Verkerk, B. J. Middelhuis, A. J. Burggraaf, Effect of grain boundaries on the conductivity of high-purity $\mathrm{ZrO}_{2} \mathrm{Y}_{2} \mathrm{O}_{3}$ ceramics, Solid State Ion. 6 (2) (1982) 159-170. doi:10.1016/0167-2738(82)90083-2.

[43] X. Guo, Solute segregations at the space-charge layers of stabilized zirconia: an opportunity for ameliorating conductivity, J. Eur. Ceram. Soc. 16 (5) (1996) 575-578. doi:10.1016/0955-2219(95)00162-X.

[44] M. Aoki, Y.-M. Chiang, I. Kosacki, L. J.-R. Lee, H. Tuller, Y. Liu, Solute Segregation and Grain-Boundary Impedance in High-Purity Sta-

口 bilized Zirconia, J. Am. Ceram. Soc. 79 (5) (1996) 1169-1180. doi: 10.1111/j.1151-2916.1996.tb08569.x.

[45] C. A. J. Fisher, H. Matsubara, Oxide ion diffusion along grain boundaries in zirconia: A molecular dynamics study, Solid State Ion. 113115 (1998) 311-318. doi:10.1016/S0167-2738(98)00380-4. 
[46] H. L. Tuller, Ionic conduction in nanocrystalline materials, Solid State Ion. 131 (1-2) (2000) 143-157. doi:10.1016/S0167-2738(00) 00629-9.

[47] K.-S. Chang, Y.-F. Lin, K.-L. Tung, Insight into the grain boundary effect on the ionic transport of yttria-stabilized zirconia at elevated temperatures from a molecular modeling perspective, J. Power Sources 196 (22) (2011) 9322-9330. doi:10.1016/j.jpowsour.2011.07.085

[48] R. L. González-Romero, J. J. Meléndez, D. Gómez-García, F. L. Cumbrera, A. Domínguez-Rodríguez, A Molecular Dynamics study of grain boundaries in YSZ: Structure, energetics and diffusion of oxygen, Solid State Ion. 219 (2012) 1-10. doi:10.1016/j.ssi.2012.05.004.

[49] P. S. Manning, J. D. Sirman, R. A. De Souza, J. A. Kilner, The kinetics of oxygen transport in $9.5 \mathrm{~mol} \%$ single crystal yttria stabilised zirconia, Solid State Ion. 100 (1-2) (1997) 1-10. doi:10.1016/S0167-2738(97) 00345-7.

[50] M. S. Khan, M. S. Islam, D. R. Bates, Cation doping and oxygen diffusion in zirconia: a combined atomistic simulation and molecular dynamics study, J. Mater. Chem. 8 (10) (1998) 2299-2307. doi:10.1039/A803917H.

[51] K. Sasaki, J. Maier, Re-analysis of defect equilibria and transport parameters in y2o3-stabilized $\mathrm{ZrO} 2$ using EPR and optical relaxation, Solid State Ionics 134 (3-4) (2000) 303-321.

[52] G. Knöner, K. Reimann, R. Röwer, U. Södervall, H.-E. Schaefer, Enhanced Oxygen Diffusivity in Interfaces of Nanocrystalline $\mathrm{ZrO} 2-\mathrm{Y}_{2} \mathrm{O}_{3}$, Proc. Natl. Acad. Sci. U S A 100 (7) (2003) 3870-3873.

[53] R. P. O'Hayre, Materials Kinetics Fundamentals, Wiley, 2015.

[54] T. Bieger, H. Yugami, N. Nicoloso, J. Maier, R. Waser, Optical absorption relaxation applied to $\mathrm{SrTiO}_{3}$ and $\mathrm{ZrO}_{2}$ : An in-situ method to study trapping effects on chemical diffusion, Solid State Ion. 72, Part 2 (1994) 41-46. doi:10.1016/0167-2738(94)90122-8. 
[55] M. K. Dongare, K. Malshe, C. S. Gopinath, I. K. Murwani, E. Kemnitz, Oxidation activity and ${ }^{18} \mathrm{O}$-isotope exchange behavior of nickel oxide-

n. stabilized cubic zirconia, J. Catal. 222 (1) (2004) 80-86. doi:10.1016/j. jcat.2003.11.009.

[56] C. R. A. Catlow, M. J. Norgett, T. A. Ross, Ion transport and interatomic potentials in the alkaline-earth-fluoride crystals, J. Phys. C: Solid State Phys. 10 (10) (1977) 1627. doi:10.1088/0022-3719/10/10/007.

[57] F. R. Chien, A. H. Heuer, Lattice diffusion kinetics in $\mathrm{Y}_{2} \mathrm{O}_{3}$-stabilized cubic $\mathrm{ZrO}_{2}$ single crystals: A dislocation loop annealing study, Philos. Mag. A 73 (3) (1996) 681-697. doi:10.1080/01418619608242990.

[58] M. Kilo, R. A. Jackson, G. Borchardt, Computer modelling of ion migra-

1. tion in zirconia, Philos. Mag. 83 (29) (2003) 3309-3325. doi:10.1080/ 14786430310001605001 .

[59] M. Kilo, M. A. Taylor, C. Argirusis, G. Borchardt, B. Lesage, S. Weber, S. Scherrer, H. Scherrer, M. Schroeder, M. Martin, Cation self-diffusion of 44Ca, 88Y, and 96Zr in single-crystalline calcia- and yttria-doped zirconia, J. Appl. Phys. 94 (12) (2003) 7547-7552. doi:10.1063/1.1628379.

[60] J. Steinfeld, J. Francisco, W. Hase, Chemical Kinetics and Dynamics, 2nd Edition, Prentice Hall, 1999, p. 6.

[61] X. Guo, J. Maier, Grain Boundary Blocking Effect in Zirconia: A Schottky Barrier Analysis, J. Electrochem. Soc. 148 (3) (2001) E121-E126. doi: $10.1149 / 1.1348267$

[62] J. D. Embury, R. B. Nicholson, The nucleation of precipitates: The system Al-Zn-Mg, Acta Metall. 13 (4) (1965) 403-417. doi:10.1016/ 0001-6160(65) 90067-2.

[63] H. Holl, Effect of a sub-grain structure on precipitation-hardening in an aluminium-zinc-magnesium-chromium alloys, J. Inst. Met. 93 (1965) 364365. 







\section{TABLES}

Table 1: A summary of the experimental conditions for the reduction reactions.

\begin{tabular}{ccccc}
\hline Specimen & $\begin{array}{c}\text { Reduction } \\
\text { Temperature } \\
\end{array}$ & $\log 10 P_{\mathbf{H}_{2}}$ & $\log 10 P_{\mathbf{H}_{2} \mathbf{O}}$ & $\begin{array}{c}\text { Reduction } \\
\text { Time }\end{array}$ \\
\hline $1000^{\circ} \mathrm{C}, 10^{-19} \mathrm{~atm}$ & 1000 & -1.70 & -3.49 & $0.5,1,5,10,25$, \\
& & & & $50,66, \& 75$ \\
$1000^{\circ} \mathrm{C}, 10^{-15} \mathrm{~atm}$ & 1000 & -3.87 & -3.49 & $0.5,5,10, \& 25$ \\
$900^{\circ} \mathrm{C}, 10^{-19} \mathrm{~atm}$ & 900 & -2.54 & -3.49 & $0.5,5,10, \& 25$ \\
$800^{\circ} \mathrm{C}, 10^{-19} \mathrm{~atm}$ & 800 & -3.54 & -3.49 & $0.5,5,10, \& 25$ \\
\hline
\end{tabular}

Table 2: A summary of the observed blocking temperatures with calculated particle diameter shows coarsening of superparamagnetic metallic $\mathrm{Ni}^{0}$ particles.

\begin{tabular}{ccc}
$\begin{array}{c}\text { Reduction } \\
\text { Time }\end{array}$ & $\begin{array}{c}\text { Blocking } \\
\text { Temperature }\end{array}$ & $\begin{array}{c}\text { Particle } \\
\text { Diameter } \\
\text { h }\end{array}$ \\
\hline 10 & 11 & nm \\
25 & 38 & 4 \\
50 & 92 & 7 \\
\hline
\end{tabular}

Table 3: A summary of the parabolic rate of stage 1 reduction, comparing the measured rate to the corrected rate that accounts for the extra distance that oxygen vacancies diffuse along porosity.

Reduction k (uncorrected) $\quad \mathrm{k}$ (corrected) Calculated Diffusivity

Condition [51]

\begin{tabular}{cccc} 
& $\mathrm{cm}^{2} / \mathrm{s}$ & $\mathrm{cm}^{2} / \mathrm{s}$ & $\mathrm{cm}^{2} / \mathrm{s}$ \\
\hline $1000^{\circ} \mathrm{C}, 10^{-19} \mathrm{~atm}$ & $4.10 \times 10^{-7}$ & $1.18 \times 10^{-6}$ & $9.83 \times 10^{-6}$ \\
$1000^{\circ} \mathrm{C}, 10^{-15} \mathrm{~atm}$ & $5.62 \times 10^{-8}$ & $1.62 \times 10^{-7}$ & $9.83 \times 10^{-6}$ \\
$900^{\circ} \mathrm{C}, 10^{-19} \mathrm{~atm}$ & $1.90 \times 10^{-7}$ & $2.55 \times 10^{-7}$ & $5.16 \times 10^{-6}$ \\
\hline
\end{tabular}




\section{FIGURES}

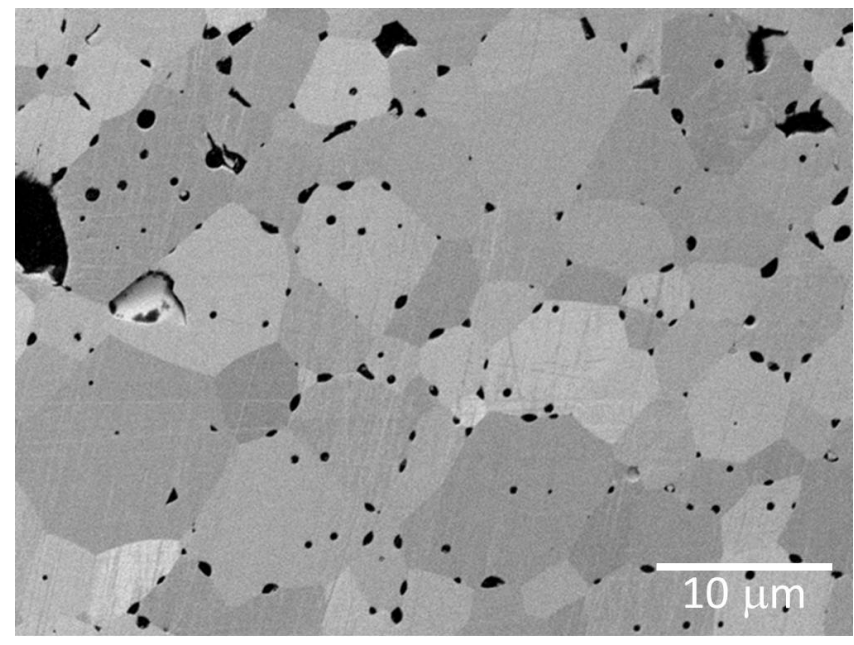

Figure 1: SEM micrograph showing the as-sintered polycrystalline microstructure of 0.5 molar $\%$ Ni-doped 10YSZ that contains average grains approximately $5 \mu \mathrm{m}$ and approximately $5 \%$ pre-existing porosity.

(a)



(c)

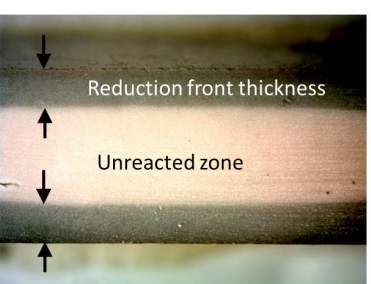

(e)



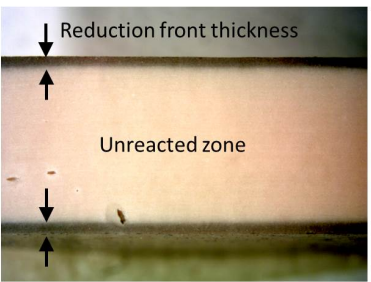

(d)

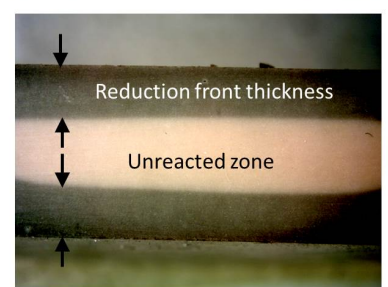

$\overline{2 \mathrm{~mm}}$

Figure 3: Optical micrographs of cross-sectioned $900^{\circ} \mathrm{C}, P_{\mathrm{O}_{2}} \sim 10^{-19}$ atm reduced pellets. The reaction front moves inward from the exterior surfaces and results in a color change in the cross-section (tan to gray) as metallic $\mathrm{Ni}^{0}$ particles form. The extent of reduction is shown for various soak times: (b) $0.5 \mathrm{~h}$, (c) $5 \mathrm{~h}$, (d) $10 \mathrm{~h}$, and (e) $25 \mathrm{~h}$ when the reaction front has almost swept the entire cross-sectional thickness. 
Figure 4: Plot of the square extent of reaction versus time for the various experimental conditions: $1000^{\circ} \mathrm{C}, P_{\mathrm{O}_{2}} \sim 10^{-19} \mathrm{~atm}, 900^{\circ} \mathrm{C}, P_{\mathrm{O}_{2}} \sim 10^{-19}$ atm, $1000^{\circ} \mathrm{C}$, and $P_{\mathrm{O}_{2}} \sim 10^{-15}$ atm. The thickness of the reaction layer squared varies linearly as a function of reduction time, indicating that the reaction is diffusion limited (parabolic kinetics). As expected, the highest rate (steepest slope) occurs in the $1000^{\circ} \mathrm{C} 10^{-19}$ atm reduced pellet. The error bars represent standard error. The plateau in the

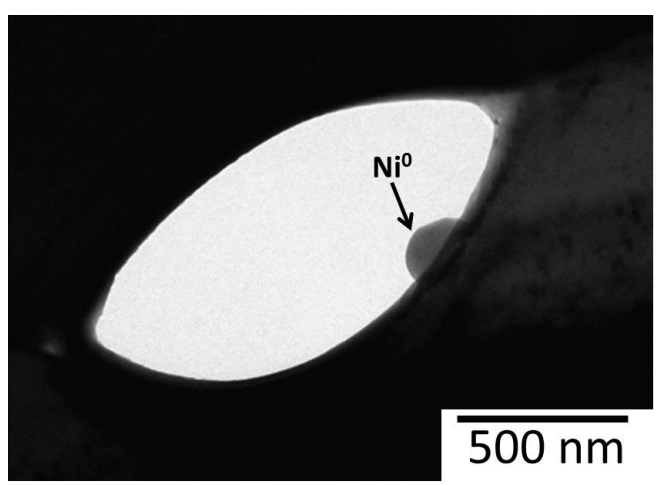

Figure 5: TEM micrographs of reduced specimen after $5 \mathrm{~h}$ at $1000^{\circ} \mathrm{C}$ in $2 \% \mathrm{H}_{2}$ showing faceted metallic $\mathrm{Ni}^{0}$ particle in pre-existing pore that is representative of stage 1 reduction. 


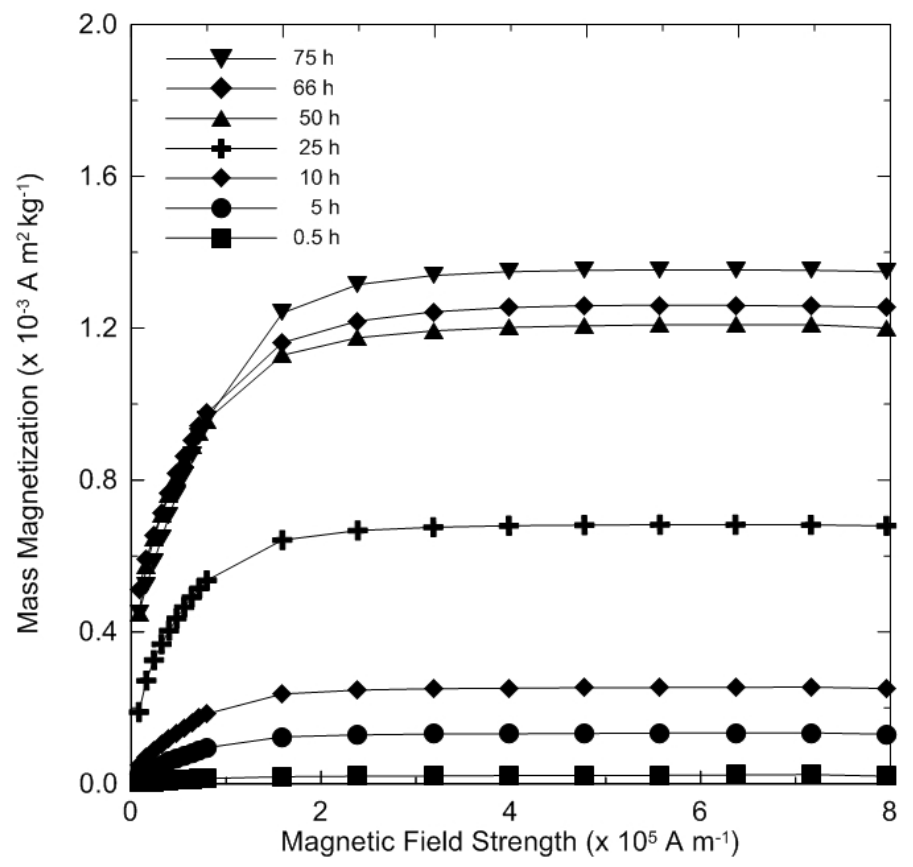

Figure 6: Magnetization versus field curves taken at $100 \mathrm{~K}$ showing the magnetic saturation for reductions at various times in $1000^{\circ} \mathrm{C}, P_{\mathrm{O}_{2}} 10^{-19}$ atm. The magnitude of magnetic saturation correlates to the mass of metallic $\mathrm{Ni}^{0}$ due to reduction. As more $\mathrm{Ni}^{0}$ particles form with longer soak times the magnetic saturation increases. The precision of the SQUID magnetometry measurement is represented by the size of the data points. 


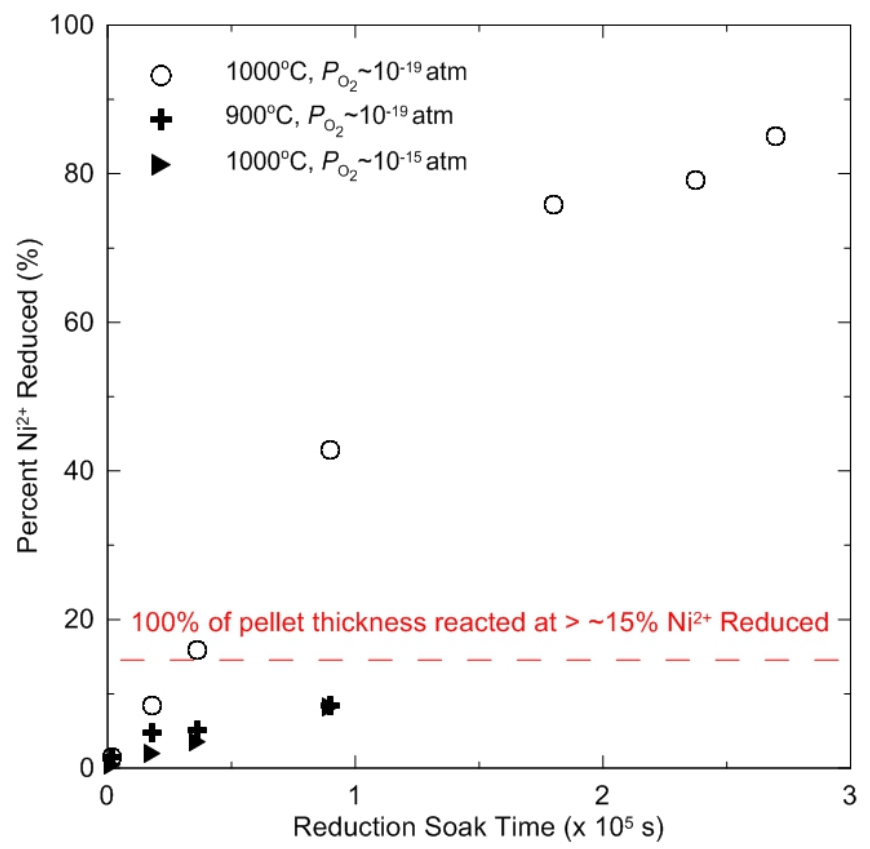

Figure 7: Plot showing the percent of reduced metallic $\mathrm{Ni}^{0}$ versus soak time calculated from the saturation of mass magnetization for various reduction treatements. The pellets reduced at $1000^{\circ} \mathrm{C}, P_{\mathrm{O}_{2}} \sim 10^{-19}$ atm show deviation from a linear trends as soak times increase indicating there is a change in reduction kinetics. A linear trend is observed for the other experimental conditions which did not show microstructural features associated with stage 3 reduction at these soak times. The precision of the SQUID magnetometry measurement is represented by the size of the data points. The absolute value depends on the cross-section of pellet, but the trend is linear. 
(a)

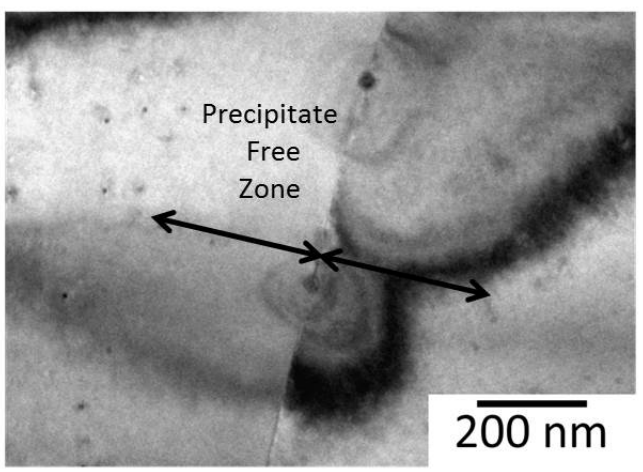

(b)

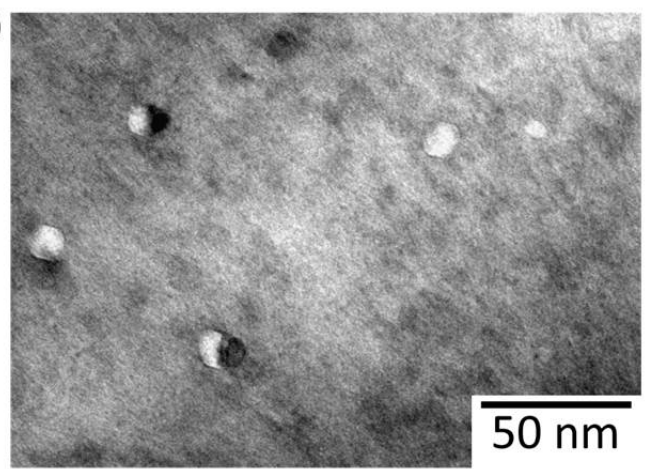

Figure 8: TEM micrographs of reduced specimen after $25 \mathrm{~h}$ at $1000^{\circ} \mathrm{C}, P_{\mathrm{O}_{2}} \sim 10^{-19} \mathrm{~atm}$ showing stage 2 and 3 reduced microstructural features, including (a) YSZ grain boundary with coarsened metallic $\mathrm{Ni}^{0}$ particles and increased strain contrast representative of late stage 2 reduction and (b) interior of YSZ grain with superparamagnetic $\mathrm{Ni}^{0}$ particles in voids representative of stage 3 reduction. 
(a)

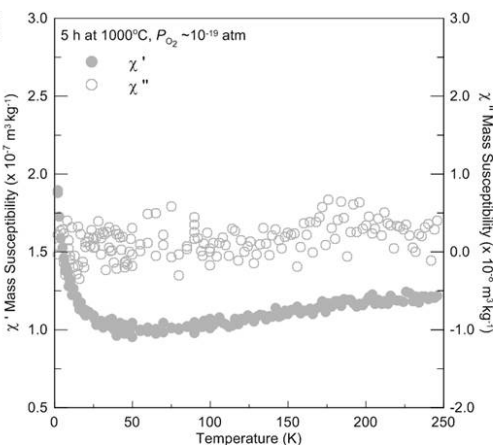

(c)

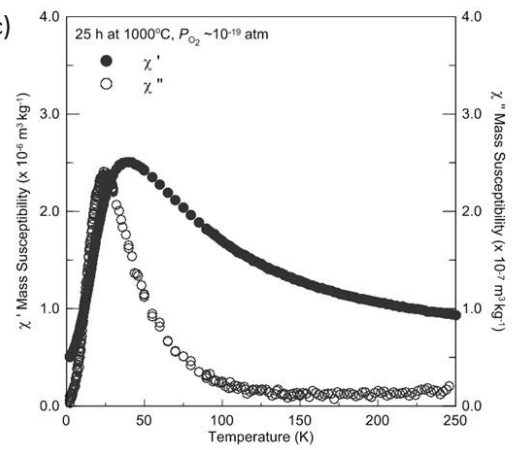

(b)

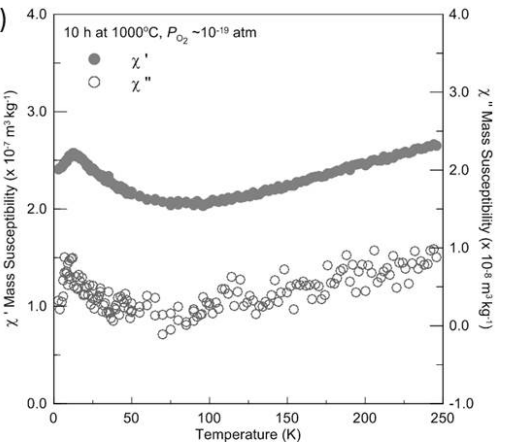

(d)

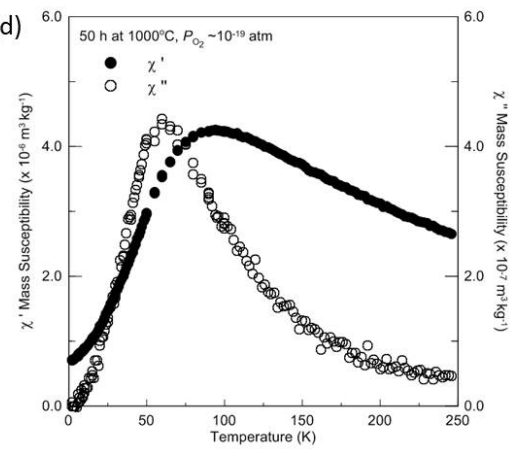

Figure 9: Real $\chi^{\prime}$ and imaginary $\chi^{\prime \prime}$ components of the AC susceptibility for 5, 10, 25, and $50 \mathrm{~h}$ soak times. The $\chi^{\prime}$ for the $5 \mathrm{~h}$ soak shows a combination of $\mathrm{Ni}^{2+}$ and large metallic $\mathrm{Ni}^{0}$ particles (gradual increase after $100 \mathrm{~K}$ ). The maximum in $\chi^{\prime}$ is indicative of $\mathrm{Ni}^{0}$ particle size, where lower temperatures correspond with superparamanetic $\mathrm{Ni}^{0}$ particles. The peak at 11 $\mathrm{K}$ in the $10 \mathrm{~h}$ soak shifts to higher temperatures as soak time increases, indicative of metallic $\mathrm{Ni}^{0}$ particle growth. Note that the scale of the $\mathrm{Y}$-axis is 10 times larger in the 25 and $50 \mathrm{~h}$ soak times than the 5 and $10 \mathrm{~h}$ soak times. The increased scale is indicative of the strong signal due to the increasing mass of superparamanetic $\mathrm{Ni}^{0}$ particles at longer reduction times. The precision of the SQUID magnetometry measurement is represented by the size of the data points. 
(a)

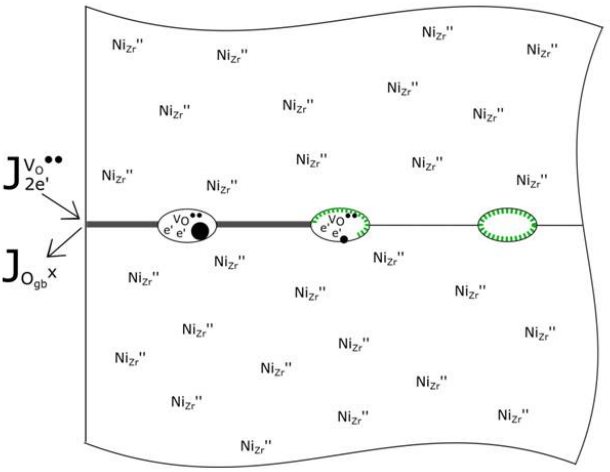

(b)

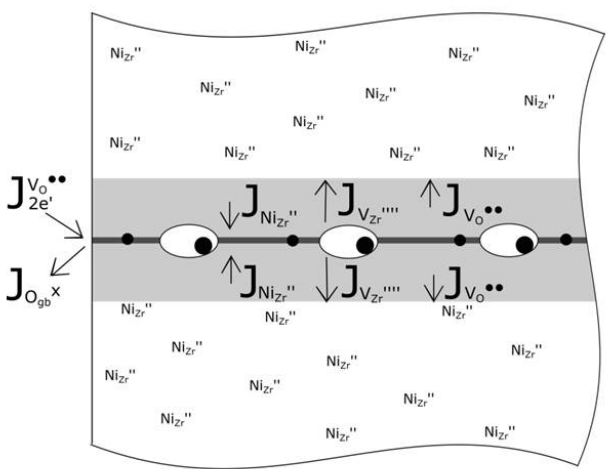

(c)

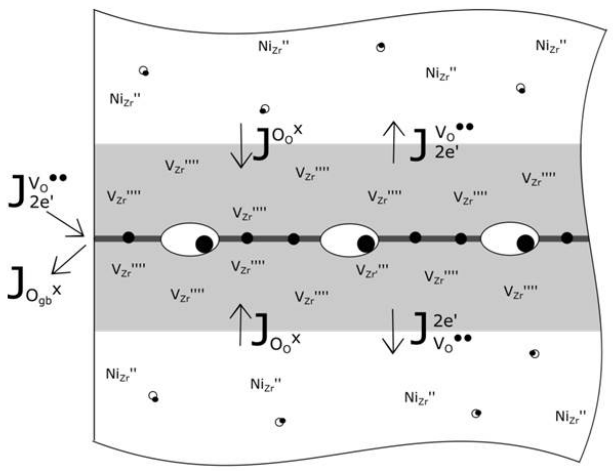

Figure 10: Schematic of the stages of reduction in polycrystalline Ni-doped $10 \mathrm{YSZ}$ at $1000^{\circ} \mathrm{C}$. Electronic defects are introduced at the surface. In stage 1 (a) oxygen vacancies and electrons diffuse along the grain boundaries as charge neutral species and react with $\mathrm{Ni}^{2+}$ in pre-existing pores. In stage 2 (b) $\mathrm{Ni}^{2+}$ on $\mathrm{Zr}^{4+}$ sites diffuse to the grain boundaries where it reacts with electrons to form metallic $\mathrm{Ni}^{0}$ and drives a counter flux of zirconium and oxygen vacancies into the grain interiors. In stage 3 (c) superparamagnetic $\mathrm{Ni}^{0}$ forms due to the increased concentration of vacancies in the grain interiors that lower the nucleation energy by creating a free surface (void) and coarsen with longer times. The shaded region around the grain boundary indicates the space charge layer. 

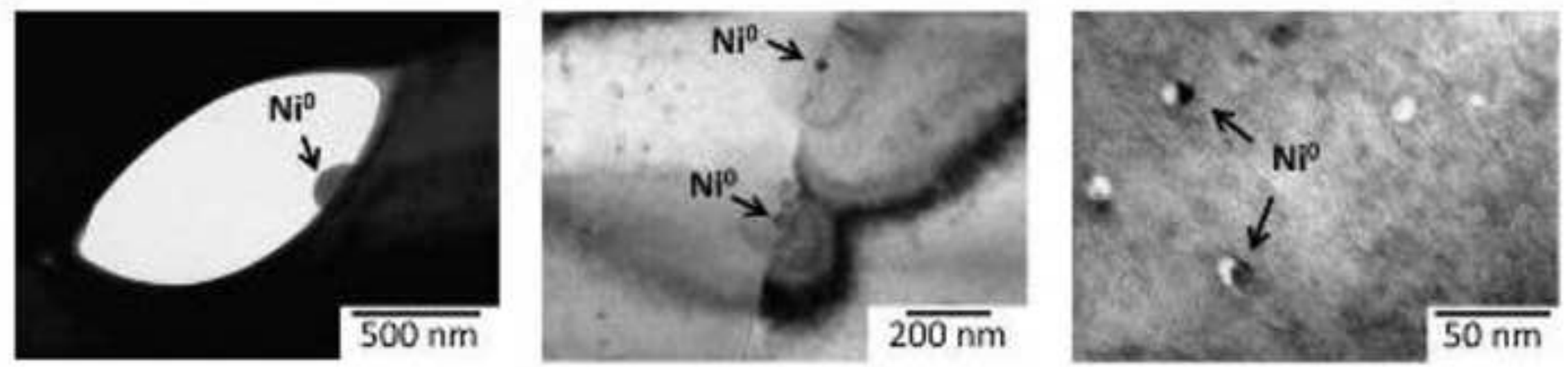

$>100 \mathrm{~nm}$ metallic $\mathrm{Ni}^{3}$ particles form in pre-existing pores
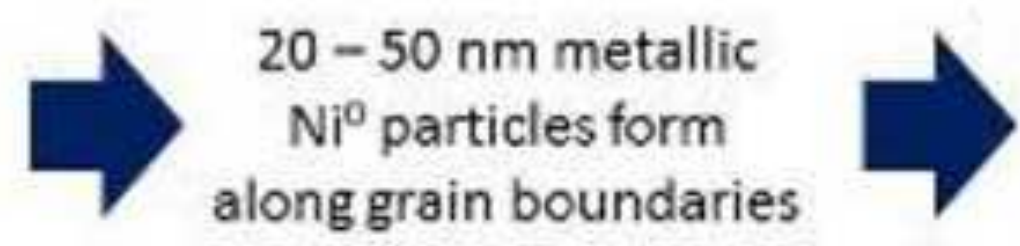

$<10 \mathrm{~nm}$ metallic $\mathrm{Ni}^{\mathrm{D}}$ particles form along grain interiors 